\title{
El efecto de la proximidad del bosque sobre el control biológico de pastos en el Noroeste de Mato Grosso, Brasil: un análisis coste-beneficio para políticas de uso del suelo
}

\author{
The effect of the proximity of the forest on the biological control \\ of pastures in the Northwest of Mato Grosso, Brazil: \\ a cost-benefit analysis for land use policies \\ Del Arco, P. ${ }^{1 *}$, May, P. $^{2}$, Rusch, G. ${ }^{3}$ \\ ${ }^{1}$ Instituto de Economía, Universidad Federal de Rio de Janeiro, Av. Pasteur, 250 - Rio de Janeiro, Brasil \\ ${ }^{2}$ Universidad Federal Rural de Rio de Janeiro, Av. Presidente Vargas 417, Rio de Janeiro, Brasil \\ ${ }^{3}$ Norwegian Institute for Nature Research, 5685 Sluppen, NO-7485 Trondheim, Norway \\ *Autor para correspondencia: pablo.delarco@gmail.com
}

\begin{abstract}
Resumen
Este estudio pretende generar información para dueños de tierras, productores rurales, técnicos de extensión rural y formuladores de políticas públicas, que permita integrar el valor generado por el bosque en la toma de decisiones con respecto a la gestión de agroecosistemas del Noroeste de Mato Grosso (Brasil). Para tal fin, se ha analizado el control biológico de plagas proporcionado por los bosques a los pastos en el municipio de Cotriguaçu, considerado representativo. Este servicio ecosistémico (SE) puede beneficiar de forma significativa la ganadería extensiva: una de las principales actividades económicas y vectores de deforestación de la región.

El nivel de control de plagas potencialmente ejercido por el bosque, su valor y los criterios para maximizarlo, han sido evaluados a través de la correlación entre la proximidad del bosque, el nivel de infestación de salivazos (Homoptera: Cercopidae) en los pastos y la pérdida económica estimada. Se han elaborado diferentes escenarios, en términos de estrategias de conservación y relación coste-beneficio, a partir del valor estimado para este servicio ecosistémico y del coste de oportunidad de conservar los remanentes de bosque.
\end{abstract}

\section{Summary}

This study aims to generate information for landowners, rural producers, rural extension technicians and public policymakers, to integrate the value generated by the forest in decision-making regarding the management of agroecosystems in the Northwest of Mato Grosso ( Brazil). To this end, the biological control of pests provided by forests to pastures in the municipality of Cotriguaçu, considered representative, has been analyzed. This ecosystem service (ES) can significantly benefit extensive livestock farming: one of the main economic activities and vectors of deforestation in the region.

The level of pest control potentially exercised by the forest, its value and the criteria for maximizing it, have been evaluated through the correlation between the proximity of the forest, the level of infestation of spittlebugs (Homoptera: Cercopidae) in the pastures and the estimated economic loss. Different scenarios have been developed, in terms of conservation strategies and cost-benefit ratio, based on the estimated value for this ecosystem service and the opportunity cost of conserving forest remnants

Palabras clave: Amazonia, ganadería, plagas de pastos, valoración de control biológico.

Keywords: Amazon, livestock, pasture pests, biological control valuation 


\section{Introducción}

Como los servicios ecosistémicos de soporte y regulación son ampliamente dependientes de factores biológicos, la resiliencia de los agroecosistemas depende de su integridad y biodiversidad. De esta forma, la estabilidad del agroecosistema y de su producción podría ser aumentada incrementando la biodiversidad funcional (Altieri, 1999) y la conectividad entre los fragmentos de bosque.

El Código Forestal brasileño fue reformado recientemente, introduciendo cambios contrarios a la recomendación de las principales sociedades científicas del país (Silva et al., 2011). En ese contexto de flexibilización de la legislación ambiental, este estudio ofrece información que puede llevar a los responsables de la toma de decisiones a considerar el valor del bosque en pie en la gestión de los agroecosistemas. Así, esta investigación podría resultar útil frente al dilema entre generar beneficios ambientales globales de largo plazo, a través de la conservación del bosque, o beneficios económicos locales de corto plazo, a través de su tala y substitución por pastos. Los productores no están interesados en la conservación si significa pérdida de área productiva, pero tal vez lo estarían si se demostrase que sus pastos pueden beneficiarse de la proximidad del bosque. De esta forma, los productores podrían formar parte de una solución de beneficio global y local.

Teniendo esto en cuenta, el estudio documenta los beneficios económicos locales asociados al control de plagas que el bosque proporciona a los pastos. Esta es una cuestión clave en el noroeste de Mato Grosso, ya que la ganadería es una de las actividades más relevantes para la economía local. La extensividad de la actividad y el empleo generalizado de malas prácticas de manejo de pastos y ganado determinan el bajo rendimiento que obtiene en la región.

Algunos autores sugieren que la ganadería extensiva subsiste localmente debido a la disponibilidad de crédito para la expansión del rebaño, la baja demanda de insumos y, eventualmente, la posibilidad de cortar el bosque, vender la madera y ampliar el área de pasto, entre otros factores (Margulis, 2003).

Los salivazos (Homoptera, Cercopidae) son la principal plaga que afecta a las gramíneas en la América tropical. Causa daños a través de la succión de la savia y la inyección de secreciones salivales en tejidos vegetales que realizan las ninfas $\mathrm{y}$, principalmente, los adultos (Valério, 2009). Como resultado, se produce una caída drástica en la producción de pasto y de su calidad, por lo que éste pierde capacidad de carga. En el caso de pastos sobre suelos degradados o con déficit hídrico, las gramíneas son más atacadas por estos insectos (Ibid, 2009). En este sentido, la importancia de los servicios ecosistémicos proporcionados por el bosque a la agricultura y la ganadería es clara. Entre estos servicios se encuentran la regulación microclimática, hidrológica y del ciclo de nutrientes, el control de la erosión y otros factores. Sin embargo, los agricultores no perciben claramente estos beneficios y tienden a recurrir al tratamiento químico o a la quema de pastos para eliminar la plaga y aumentar la productividad en el corto plazo.

La gran magnitud de los daños causados por los salivazos en el noroeste de Mato Grosso, la tendencia de estos daños a aumentar, según lo relatado por agri- 
cultores y técnicos locales, y el fracaso de los intentos de controlar esta plaga por fuego, plaguicidas e incluso hongos- han generado una demanda local de métodos de control alternativos. Esto puede interpretarse como la necesidad de garantizar una producción sostenible de pastos en la región.

En lugar de buscar maneras de "matar más salivazos", o desarrollar pastizales resistentes a este insecto, podemos promover pastos sanos y mantener poblaciones de salivazo controladas dentro de una red trófica equilibrada (Driesche, 2007). Para que esto sea posible, es necesario demostrar a los propietarios de tierras y formuladores de políticas públicas el valor de los servicios ecosistémicos proporcionados por el bosque a los agroecosistemas.

En este aspecto, existe amplia constancia en la literatura consultada de cómo se puede interferir en el equilibrio de los agroecosistemas, y por tanto sobre la incidencia de plagas, a través de la gestión del paisaje:

- Según Rodrigues (1998), en bosques tropicales se puede percibir el efecto de borde hasta aproximadamente unos $35 \mathrm{~m}$ de distancia. Partiendo de esa premisa, establecer corredores de vegetación entre las grandes manchas de bosque de, al menos, $70 \mathrm{~m}$ de anchura permitirían favorecer la conectividad del paisaje y la resiliencia del agroecosistema.

— Los corredores de vegetación que incluyan árboles y arbustos grandes son una barrera efectiva contra la propagación de los insectos que vuelan a baja altura como los salivazos (Sujii, et al., 2000). Esto debe ser considerado en el diseño de áreas de pastoreo y en la delimitación de las fincas. Los corredores que no sigan cursos de agua deben ser preferentemente tangenciales a la dirección predominante del viento, para dificultar la dispersión de los insectos (Altieri and Nicholls, 2010).

- También se puede favorecer la presencia de los enemigos naturales de los salivazos en los pastos a través de bandas de vegetación nativa que les proporcionen recursos clave. En diferentes tipos de cultivos se han utilizado con éxito bandas de entre 1.5 y 9 m, según Altieri and Nicholls (2010).

- Con vistas a maximizar el rendimiento neto de las explotaciones ganaderas, reduciendo los daños provocados por plagas, del 20 al 25\% de la superficie productiva de las mismas debería estar ocupada por bosques y manchas de bosque (Porfirio da Silva, 2006). Cabe destacar que esta recomendación tiene fines productivos, no conservacionistas. Por tanto, es a priori independiente - aunque puedan solaparse - de otras superficies de bosque nativo que la finca preserve fuera de la superficie productiva para cumplir con la legislación ambiental brasileña. Dicha legislación establece que las fincas rurales deben mantener un determinado porcentaje de su superficie como reserva de bosque nativo. Las características de estas reservas varían en función de la región y del tamaño de la propiedad, entre otros factores. 
Partiendo de la revisión bibliográfica realizada, este estudio se propone hacer una estimación de los daños que provocan los salivazos en el municipio de Cotriguaçu (considerado representativo del Noroeste de Mato Grosso), así como de la potencial reducción de los mismos que podría ser lograda a través de la gestión del paisaje, gracias al control biológico de plagas proporcionado por los bosques a los pastos. Se pretende generar dos tipos de resultados: en primer lugar, contribuir al desarrollo de las bases para una gestión del paisaje más eficiente e integrada en los agroecosistemas de la región, y, en segundo lugar, promover un cambio en la percepción de los propietarios sobre sus incentivos para deforestar, permitiéndoles incluir en su toma de decisiones el valor agregado por el bosque a la actividad pecuaria. Como resultado final, este trabajo pretende promover una mayor compatibilidad entre la ganadería y la conservación de la biodiversidad dentro del paisaje productivo, en una de las regiones más amenazadas de la cuenca amazónica.

\section{Estimación del daño económico causado por salivazos}

Para evaluar la importancia de controlar las poblaciones de salivazos se realizó una encuesta a productores locales, a través de la cual se estimaron las pérdidas económicas provocadas por el insecto en la temporada anterior. Los productores entrevistados fueron escogidos por los técnicos extensionistas locales, que los consideraron representativos del municipio de Cotriguaçu (Tab. 1). De acuerdo con los datos obtenidos, las pérdidas podrían alcanzar $240 \mathrm{R} \$ \mathrm{ha}^{-1} \mathrm{año}^{-1}$, ó $167 \mathrm{R} \$ \mathrm{ha}^{-1} \mathrm{año}^{-1}$ excluyendo los valores atípicos.

Tabla 1. Resumen de pérdidas económicas causadas por salivazo según los entrevistados. $1 \mathrm{R} \$=2.70 €$

\begin{tabular}{|c|c|c|c|}
\hline \multirow{2}{*}{ País } & Producción & \multicolumn{2}{|c|}{$\begin{array}{c}\text { Pérdidas económicas causadas por salivazo } \\
\mathrm{R} \$ \text { año }^{-1}\end{array}$} \\
& & 31800 & 1223.1 \\
\hline Propietario 1 & Leche & 44700 & 298.0 \\
\hline Propietario 2 & Carne & 181020 & 289.2 \\
\hline Propietario 3 & Carne & 47827 & 208.9 \\
\hline Propietario 4 & Carne & 157000 & 196.3 \\
\hline Propietario 5 & Carne & 20115 & 92.4 \\
\hline Propietario 6 & Carne y leche & 22450 & 44.9 \\
\hline Propietario 7 & Carne y leche & 50625 & 42.2 \\
\hline Propietario 8 & Alquiler pasto & 50000 & 5.2 \\
\hline Propietario 9 & Carne & 175 & 0.6 \\
\hline Propietario 10 & Carne & & 240 \\
\hline
\end{tabular}

Media: $240 \mathrm{R} \$$ ha $^{-1} \mathrm{año} \mathrm{o}^{-1}$

Esta estimación trata de incorporar los diversos efectos económicos negativos causados por el ataque del salivazo, y pedimos a los entrevistados que diferenciasen las pérdidas provocadas por el insecto de aquellas causadas por otras eventua- 
lidades, como el ataque de otras plagas o el déficit hídrico durante el periodo seco. Esta estimación incluye tanto los costes directos de mantener la viabilidad del sistema de producción (alquiler extra de pastos, alimentación suplementaria, recuperación de pastos, entre otros), como la pérdida de ingresos (pérdida de peso del ganado, pérdida de excedente de pastos para alquilar, entre otros).

La tasa de cambio en el período de obtención de los datos, empleada a lo largo del artículo, es: $1 \mathrm{R} \$=2.70 €$

\section{Estimación del control biológico proporcionado por el bosque: nivel de prestación del servicio ecosistémico y valor asociado}

Se ha estimado el valor del control biológico evaluando la relación entre el nivel de infestación de salivazos (sin diferenciar género ni especie), la pérdida económica anual estimada y la proximidad del bosque. Para ello, se midió el nivel de infestación de ninfas y adultos de salivazo en un conjunto de cinco parcelas de una hectárea $(100 \times 100 \mathrm{~m})$. Estas parcelas estaban localizadas en propiedades ganaderas con diferentes mosaicos de bosque o bosquetes y pastos de Brachiaria brizantha (Fig. 1). En cada parcela se establecieron 25 puntos de muestreo en una malla
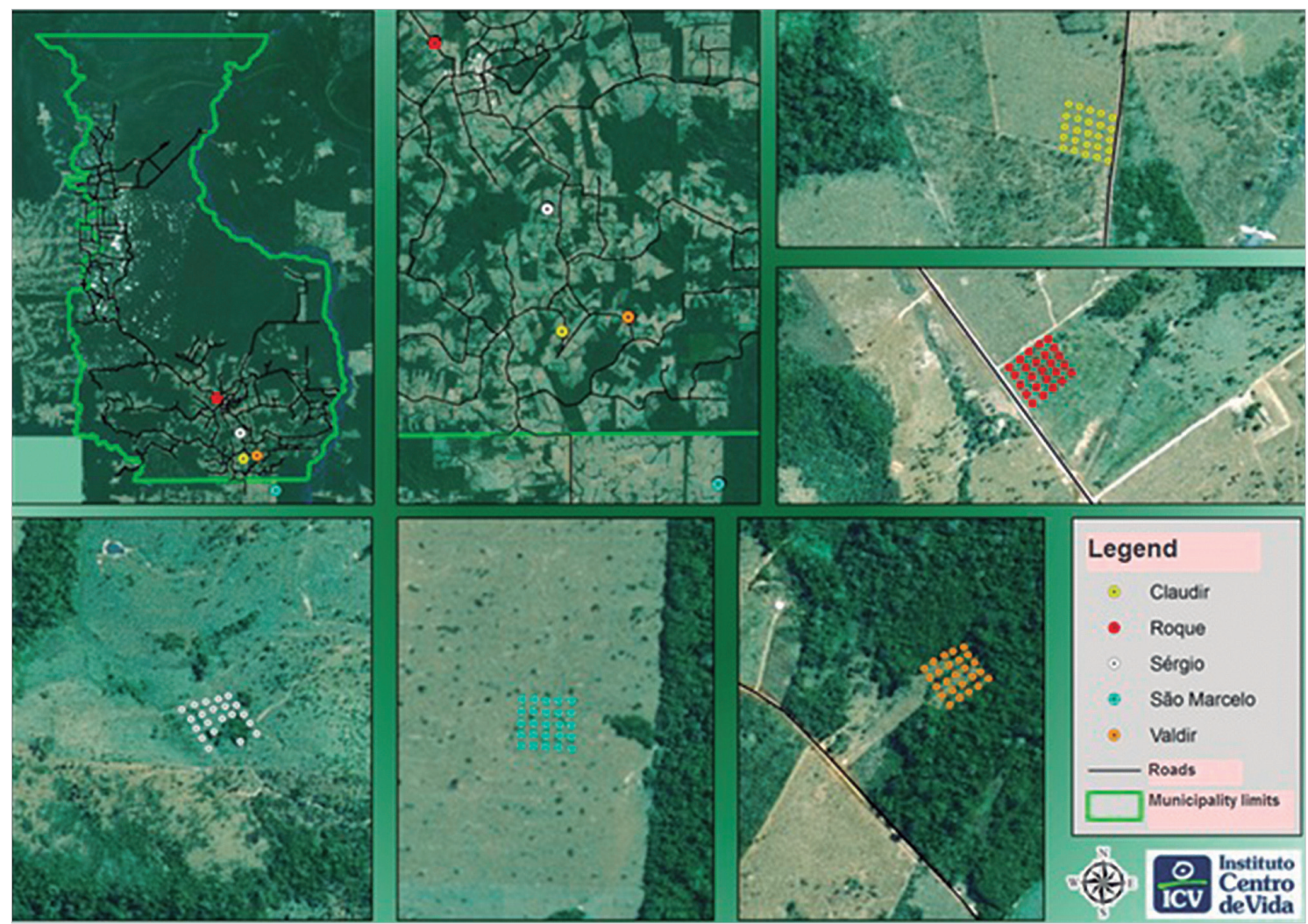

Figura 1. Puntos de muestreo georreferenciados en fincas de Cotriguaçu. 
regular de 25 x $25 \mathrm{~m}$. Las muestras se tomaron una vez por semana durante tres semanas, en la estación húmeda.

(El nivel de infestación de las ninfas se midió usando un cuadrado de alambre de $25 \mathrm{~cm}$ x $25 \mathrm{~cm}$. Se fijó aleatoriamente en el suelo, cerca de cada punto de muestreo, y se contó el número de espumas — donde los salivazos permanecen en grupos durante la fase de ninfa, como protección ante los enemigos naturales y la desecación- - El nivel de infestación de los adultos se midió utilizando una red entomológica, realizando 10 movimientos de barrido cerca de cada punto de muestreo (Valério, 2002).

El nivel de control biológico proporcionado por el bosque se ha estimado como la diferencia entre el nivel de infestación de adultos detectado en cada parcela y el nivel de infestación detectado en las parcelas de control, sin la presencia de bosque. Esta comparación fue realizada en términos relativos y el nivel de infestación medio de las parcelas control fue considerado el valor de referencia $(100 \%)$.

Posteriormente se ha estimado el valor del control biológico para cada tipo de mosaico bosque-pasto. Para ello, se han tomado como referencia un nivel mínimo y máximo de infestación para los cuales se conocen las pérdidas económicas y se ha asumido una relación lineal entre ambas variables. Consideramos como valor mínimo la ausencia de salivazos que, por lo tanto, no causan pérdidas económicas $(0$ $\left.\mathrm{R} \$ \mathrm{ha}^{-1} \mathrm{año}^{-1}\right)$. Consideramos como valor máximo el nivel de infestación detectado en pastos sin bosque, asumiendo que en ellos no se da control biológico. Hemos asumido que las pérdidas asociadas a estos pastos corresponden a las pérdidas promedio estimadas a través de cuestionarios para la región $\left(240 \mathrm{R} \$ \mathrm{ha}^{-1} \mathrm{año}^{-1}\right)$.

Para estimar el valor del control biológico proporcionado por el bosque en cada mosaico estudiado se han comparado las pérdidas económicas que causa el salivazo en cada tipo de mosaico bosque-pasto con las pérdidas que causa en las parcelas de control, sin bosque (Tab. 2).

\section{El valor del control biológico proporcionado por el bosque $y$ el coste de oportunidad de mantenerlo en pie}

Para evaluar la contribución potencial del control biológico proporcionado por el bosque a la economía local, se identificaron en la literatura valores del coste de oportunidad de mantener el bosque en pie en el municipio. Estos valores fueron determinados por la rentabilidad neta de la ganadería.

Agrosuisse (2010), utilizando datos de Anualpec (2010), calculó un rendimiento neto asociado a la ganadería en el municipio de $98.30{\mathrm{R} \$ \mathrm{ha}^{-1} \text { año }}^{-1}$. Según Reydon (2011) este valor alcanza $120 \mathrm{R} \$ \mathrm{ha}^{-1} \mathrm{año}^{-1}$. Finalmente, según las encuestas realizadas por el CIFOR (Sven Wunder, comunicación personal, 2014) en la región,

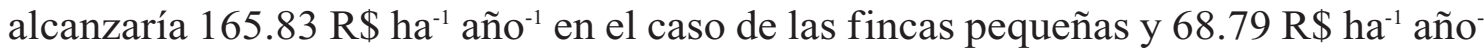
${ }^{1}$ en el caso de las fincas grandes. Ponderando este valor con la superficie relativa que ocupan las fincas de ambas categorías en Cotriguaçu, según IBGE (2006), se obtuvo un promedio ponderado para los datos del CIFOR de $103.65 \mathrm{R} \$ \mathrm{ha}^{-1} \mathrm{año}^{-1}$. Así, considerando los valores propuestos por Agrosuisse, Reydon y CIFOR, calcu- 
Tabla 2. Nivel de infestación y pérdidas económicas asociadas por tipo de mosaico. $1 \mathrm{R} \$=2.70 €$

\begin{tabular}{|c|c|c|c|c|c|c|c|}
\hline \multirow{3}{*}{$\begin{array}{l}\text { Referencia } \\
\text { de la parcela }\end{array}$} & \multicolumn{2}{|c|}{ CARACTERIZACIÓN } & \multicolumn{4}{|c|}{ NIVEL DE INFESTACIÓN MEDIO } & \multirow{3}{*}{$\begin{array}{c}\text { Pérdidas } \\
\text { económicas } \\
\text { provocadas } \\
\text { por salivazos } \\
\left(\mathrm{R} \$ \mathrm{ha}^{-1} \mathrm{año}^{-1}\right)\end{array}$} \\
\hline & \multirow{2}{*}{$\begin{array}{l}\text { Parcela } \\
\text { muestral }\end{array}$} & \multirow{2}{*}{$\begin{array}{c}\text { Entorno } \\
\text { de la parcela } \\
\text { muestral }\end{array}$} & \multicolumn{2}{|r|}{ Absoluto } & \multicolumn{2}{|c|}{ Relativo } & \\
\hline & & & $\begin{array}{c}\text { Ninfas } \\
\left(\mathrm{n} .{ }^{0} \times m^{-2}\right)\end{array}$ & $\begin{array}{c}\text { Adultos } \\
\left(\text { n. }^{\circ} \times 10 \text { capturas }\right. \\
\end{array}$ & $\begin{array}{c}\text { Ninfas } \\
(\%)\end{array}$ & $\begin{array}{c}\text { Adultos } \\
(\%)\end{array}$ & \\
\hline $\mathrm{A}^{3}$ (control) & Pasto & Pasto & 23.45 & 1.17 & 100 & 100 & 240.00 \\
\hline B & $\begin{array}{l}\text { Pasto con } \\
\text { árboles } \\
\text { dispersos }\end{array}$ & $\begin{array}{c}\text { Bosque en } 3 \\
\text { de los lados } \\
\text { y cultivo en } \\
\text { el cuarto. } \\
\text { Fuera de la } \\
\text { finca sólo } \\
\text { hay pasto }\end{array}$ & 28.40 & 0.53 & 121.1 & 45.3 & 108.72 \\
\hline $\mathrm{C}$ & $\begin{array}{l}\text { Pasto con } \\
\text { bosque } \\
\text { ripario }\end{array}$ & $\begin{array}{l}\text { Pasto con } \\
\text { algunos } \\
\text { bosquetes }\end{array}$ & 8.30 & 0.24 & 35.4 & 20.5 & 49.20 \\
\hline $\mathrm{D}$ & $\begin{array}{l}\text { Pasto con } \\
\text { múltiples } \\
\text { manchas de } \\
\text { vegetación } \\
\text { natural }\end{array}$ & $\begin{array}{c}\text { Mosaico } \\
\text { similar en el } \\
\text { entorno y } \\
\text { gran reserva } \\
\text { forestal (de } \\
\left.\text { algunos } \mathrm{km}^{2}\right) \\
\text { a } 100 \mathrm{~m} \mathrm{de} \\
\text { distancia }\end{array}$ & 3.40 & 0.03 & 14.5 & 2.6 & 6.24 \\
\hline
\end{tabular}

${ }^{2}$ Basado en la población de adultos, que son los principales responsables por el daño provocado por el salivazo. Calculado como: nivel de infestación relativo x $100^{-1}$ x 240 R \$ (valor medio de las pérdidas provocadas por salivazos en los pastos del municipio, según calculado en Tabla 1).

${ }^{3}$ Valores medios de la parcela con pasto reformado y de la parcela con pasto sin reformar.

${ }^{4} \mathrm{La}$ banda de bosque presente en 3 de los lados de la parcela de muestreo mide, respectivamente, $200 \mathrm{~m}, 400 \mathrm{~m}$ y $600 \mathrm{~m}$ de anchura. El pasto que rodea a la finca tiene un historial de altos niveles de infestación, según el propietario.

lamos un coste de oportunidad promedio de $107.32 \mathrm{R} \$ \mathrm{ha}^{-1} \mathrm{año}^{-1}$ para el municipio de Cotriguaçu.

Según estos datos, una finca con un área productiva de 10 ha que no tenga bosque, dentro o en áreas vecinas, podría obtener un rendimiento neto promedio de 1073.20 $\mathrm{R} \$ a_{n} o^{-1}$. Si la finca sufriese el ataque del salivazo y este causase pérdidas económicas similares a las estimadas a partir de los cuestionarios, los resultados serían negativos ese año, generando un balance final negativo de entre 600.90 y $1326.80 \mathrm{R} \$$.

Sin embargo, según este estudio, en el caso de que parte del área productiva de la finca de 10 ha estuviese ocupada por bosques distribuidos de manera planificada, y hubiese grandes fragmentos de bosque cercanos - como fuente de enemigos naturales de los salivazos_-, la finca podría obtener resultados positivos para el mismo periodo. Suponiendo que 2 ha de área productiva estuviesen ocupadas por bosques, la ganadería produciría un menor rendimiento económico: $858.56 \mathrm{R} \$ \mathrm{ha}^{-1}$ $a_{n} o^{-1}$. Sin embargo, las pérdidas económicas causadas por el salivazo también serían significativamente menores, como veremos a continuación. Suponiendo que la finca estuviese constituida por un mosaico de bosques y pastos similar a los que 
presentaron mayor nivel de infestación de salivazos entre los estudiados, las pérdidas serían de $869.76 \mathrm{R} \$$ año $^{-1}$, resultando en un balance negativo de $11.2 \mathrm{R} \$$ año $\mathrm{o}^{-1}$. Sin embargo, si la finca tuviese un mosaico similar al que presentó un menor nivel de infestación de salivazos en el muestreo, las pérdidas serían de $49.92 \mathrm{R} \$$ año ${ }^{-1}$, generando un balance positivo de $819.84 \mathrm{R} \$$ año $^{-1}$. Ambos resultados son significativamente mejores que el presentado por la finca que sólo tiene pasto.

La presencia de bosques cercanos a los pastos también regula el microclima y favorece el ciclo de los nutrientes, entre otros servicios ecosistémicos, contribuyendo a mejorar la productividad de los pastos próximos y la actividad ganadera aledaña (Townsend et al., 2003; Montoya and Baggio, 1992). Por tanto, posiblemente los mosaicos de bosque y pasto podrían generar un balance económico mejor de lo previsto en esta estimación, especialmente con los efectos acumulados a lo largo de sucesivos años.

\section{Beneficios económicos del control biológico en el municipio: escenarios}

Para estimar la posible reducción de las pérdidas económicas provocadas por los salivazos en el municipio, a través de la implementación de los tipos de mosaico es-

Tabla 3. Potencial reducción de las pérdidas económicas provocadas por los salivazos en el municipio de Cotriguaçu, según el tipo de mosaico establecido. $1 \mathrm{R} \$=2.70 €$

\begin{tabular}{|c|c|c|c|c|c|c|}
\hline \multirow{2}{*}{ Escenario $^{2}$} & \multirow{2}{*}{$\begin{array}{l}\text { Descripción del paisaje } \\
\text { implementado en los } \\
\text { pastos del municipio }\end{array}$} & \multicolumn{2}{|c|}{$\begin{array}{l}\text { Estimación pérdidas } \\
\text { económicas provocadas por } \\
\text { salivazo en el municipio }\end{array}$} & \multicolumn{3}{|c|}{$\begin{array}{l}\text { Potencial reducción de pérdidas } \\
\text { económicas provocadas por salivazo } \\
\text { (mosaico vs control) }\end{array}$} \\
\hline & & $\left(\mathrm{R} \$\right.$ año $\left.{ }^{-1}\right)$ & $\begin{array}{l}\text { (\% PIB de la } \\
\text { pecuaria en } \\
\text { el municipio) }\end{array}$ & $\begin{array}{l}\text { Por ha } \\
\left(\mathrm{R} \$ \mathrm{ha}^{-1}\right. \\
\left.\text { año }^{-1}\right)\end{array}$ & $\begin{array}{c}\text { Total } \\
\left(\mathrm{R} \$ \text { año }^{-1}\right)\end{array}$ & $\%$ \\
\hline A (control) & Pasto convencional & 22634400 & 32.33 & - & - & 0 \\
\hline B & $\begin{array}{c}\text { Pasto con árboles } \\
\text { dispersos. Franjas de } \\
\text { bosque repartidas en el } \\
\text { paisaje }\end{array}$ & 10253383 & 14.65 & 131.28 & 12381016,8 & 54,7 \\
\hline $\mathrm{C}$ & $\begin{array}{l}\text { Pasto con bosquetes } \\
\text { repartidos en el paisaje. } \\
\text { Ríos con bosque ripario }\end{array}$ & 4640052 & 6.63 & 190.80 & 17994348,0 & 79,5 \\
\hline $\mathrm{D}$ & $\begin{array}{c}\text { Pasto con múltiples } \\
\text { manchas de vegetación } \\
\text { natural y grandes reservas } \\
\text { de bosque repartidas en el } \\
\text { paisaje }\end{array}$ & 588494 & 0.84 & 233.76 & 22045905,6 & 97,4 \\
\hline
\end{tabular}

Para cada tipo de mosaico estudiado (denominados A, B, C, D), se ha elaborado un escenario, que lleva el mismo nombre. En cada escenario se ha supuesto que el mosaico bosque-pasto correspondiente se ha aplicado en todos los pastos del municipio. 
tudiados, se han elaborado cuatro escenarios: uno para cada tipo de mosaico bosque-pasto estudiado (tres en total) y un último que sería el escenario control (pasto sin fragmentos de bosque en el entorno). Este último se ha construido haciendo la media de los datos de las dos parcelas sin bosque incluidas en el muestreo (parcela con pasto reformado y parcela con pasto sin reformar).

En cada escenario se han calculado las pérdidas económicas provocadas por el salivazo que podrían ser evitadas al substituir todos los pastos del municipio por el mosaico bosque-pasto correspondiente en cada caso.

Para ello se ha multiplicado la estimación de pérdidas evitadas por hectárea para cada tipo de mosaico por el área ocupada por pastos en el municipio de Cotriguaçu (94 310 ha, según el Censo Agrícola de 2006).

De acuerdo con nuestro estudio, las pérdidas económicas asociadas a los salivazos en Cotriguaçu son suficientemente significativas como para amenazar la rentabilidad de la ganadería del municipio, ya que podrían alcanzar aproximadamente el 32\% de su Producto Interno Bruto (PIB).

Al mismo tiempo, mantener la vegetación nativa de forma planificada dentro y alrededor de los pastos podría regular de forma efectiva las poblaciones de salivazos mediante su control biológico, resultando en pérdidas económicas significativamente menores. Éstas podrían alcanzar entre el 0.84 y el $14.65 \%$ del PIB de la ganadería del municipio, según el tipo de mosaico establecido.

\section{Algunos criterios para la maximización del control biológico}

Con el objetivo de desarrollar criterios básicos para la planificación del paisaje que permitan maximizar el control biológico proporcionado por el bosque, examinamos a través de análisis estadístico qué variables ambientales entre las estudiadas (Tab. 4) están más relacionadas con el nivel de infestación de salivazos. Para ello fue realizado un análisis de correlación con el software Infostat. Posteriormen-

Tabla 4. Variables estudiadas.

\begin{tabular}{|c|c|}
\hline Escala de análisis & Variables \\
\hline & Número de espumas (unidades) \\
\hline \multirow[t]{4}{*}{ Punto de muestreo } & Número de adultos (unidades) \\
\hline & Altura del pasto $(\mathrm{cm})$ \\
\hline & Distancia al fragmento de bosque más próximo (m) \\
\hline & Área del fragmento de bosque más próximo $\left(\mathrm{m}^{2}\right)$ \\
\hline \multirow[t]{4}{*}{ Parcela } & Área de bosque dentro de un "buffer" de 50, 100, 200, $500 \mathrm{~m}\left(\mathrm{~m}^{2}\right)$ \\
\hline & Número de fragmentos de bosque en un "buffer" de 50, 100, 200, 500 m (unidades) \\
\hline & Tamaño medio de fragmentos de bosque en un "buffer" de 50, 100, 200, $500 \mathrm{~m}\left(\mathrm{~m}^{2}\right)$ \\
\hline & Relación perímetro/área de fragmentos de bosque en un "buffer" de 50, 100, 200, $500 \mathrm{~m}$ \\
\hline
\end{tabular}


te, se aplicó el test de "Chi-cuadrado" para determinar si las asociaciones detectadas entre variables eran superiores a las que podrían ocurrir por casualidad.

Las variables número de espumas, número de adultos y altura del pasto fueron estudiadas a partir de muestreos. Las variables restantes se evaluaron digitalizando los polígonos de bosque y los puntos de muestreo en imágenes de satélite de Google Earth para su posterior análisis con Google Earth Pro y ArcGIS.

Dentro de este segundo grupo de variables, algunas se analizaron a nivel punto de muestreo: distancia al fragmento de bosque más próximo y área del fragmento de bosque más próximo.

Las demás variables se analizaron a nivel parcela de muestreo, observando su evolución en un buffer creciente al rededor de la parcela $(50,100,200,500 \mathrm{~m}$ del borde): área de bosque en el perímetro de la parcela de muestreo, número de fragmentos de bosque en dicho perímetro, tamaño medio y relación perímetro/área de dichos fragmento (ver resultados en Tab. 5-7).

Tabla 5. Variables correlacionadas y principales resultados para nivel de significación de $0.1 \%$

\begin{tabular}{llccc}
\hline Variable (1) & \multicolumn{1}{c}{ Variable (2) } & n & Pearson & p-valor \\
\hline $\mathrm{N}^{\circ}$ adultos & Distancia a vegetación $(\mathrm{m})$ & 5 & 0.81 & 0.0963 \\
$\mathrm{~N}^{\mathrm{o}}$ adultos & $\mathrm{N}^{\circ}$ manchas $<50 \mathrm{~m}$ & 5 & -0.83 & 0.0830 \\
$\mathrm{~N}^{\mathrm{o}}$ adultos & Perímetro / área manchas $<50 \mathrm{~m}$ & 3 & -0.99 & 0.0896 \\
$\mathrm{~N}^{\circ}$ adultos & $\mathrm{N}^{\circ}$ manchas $<50 \mathrm{~m}$ & 5 & -0.95 & 0.0122 \\
$\mathrm{~N}^{\mathrm{o}}$ adultos & $\mathrm{N}^{\circ}$ manchas $<100 \mathrm{~m}$ & 5 & -0.96 & 0.0090 \\
$\mathrm{~N}^{\circ}$ adultos & $\mathrm{N}^{\circ}$ manchas $<200 \mathrm{~m}$ & 5 & -0.91 & 0.0303 \\
$\mathrm{~N}^{\circ}$ adultos & $\mathrm{N}^{\circ}$ manchas $<500 \mathrm{~m}$ & 5 & -0.86 & 0.0631 \\
$\mathrm{~N}^{\circ}$ adultos & Perímetro / área manchas $<100 \mathrm{~m}$ & 4 & -0.94 & 0.0631 \\
$\mathrm{~N}^{\circ}$ adultos & Perímetro / área manchas $<200 \mathrm{~m}$ & 5 & -0.97 & 0.0063 \\
\hline
\end{tabular}

Tabla 6. Test de Chi-cuadrado para la variable "número de espumas"

\begin{tabular}{lccc}
\hline \multicolumn{1}{c}{ Variable } & Chi-cuadrado & Grados de libertad & p-valor \\
\hline Semana de muestreo & 10.26 & 2 & 0.0059 \\
Distancia a polígono de vegetación más próximo & 14.00 & 1 & 0.0002 \\
Área del polígono de vegetación más próximo & 5.48 & 1 & 0.0192 \\
Relación perímetro: área de vegetación $>50 \mathrm{~m}$ & 278.14 & 1 & $<0.0001$ \\
\hline
\end{tabular}

Tabla 7. Test de Chi-cuadrado para la variable "número de adultos"

\begin{tabular}{lccc}
\hline \multicolumn{1}{c}{ Variable } & Chi-cuadrado & Grados de libertad & p-valor \\
\hline Semana de muestreo & 10.66 & 2 & 0.0048 \\
Distancia a polígono de vegetación más próximo & 41.88 & 1 & $<0.0001$ \\
Área del polígono de vegetación más próximo & 8.35 & 1 & 0.0039 \\
Relación perímetro : área de vegetación $>50 \mathrm{~m}$ & 273.02 & 1 & $<0.0001$ \\
\hline
\end{tabular}


Según los resultados obtenidos, podemos comprobar que cuanto menor es la distancia hasta el fragmento de bosque más próximo, menor es la población de salivazo adulto. El mayor número de manchas de bosque en todas direcciones y la mayor relación perímetro/área están fuertemente asociados a menores poblaciones de salivazo en fase de ninfa y de adulto.

Esta relación se cumple de forma especialmente clara en los primeros $50 \mathrm{~m}$, sigue siendo relevante entre los 50 y los $200 \mathrm{~m}$, y se percibe, aunque de forma sutil, entre los 200 y los $500 \mathrm{~m}$, último buffer estudiado en el entorno de la parcela. Sin embargo, se percibe que la forma y tamaño de la mancha de bosque parece más relevante a corta distancia para adultos (los primeros $50 \mathrm{~m}$ ), y a media distancia para ninfas (100 y $200 \mathrm{~m})$.

A partir de la comparación de los dos análisis, se concluye que poblaciones menores de ninfas y adultos están asociadas de manera estadísticamente significativa a:

- Distancias menores a la mancha de bosque o bosquete más cercano, siendo el efecto más fuerte en los primeros $50 \mathrm{~m}$.

- Mayor número de manchas de bosque o bosquetes.

- Manchas de bosque o bosquetes de tamaño pequeño (tamaño mínimo considerado: $50 \mathrm{~m}^{2}$ ) y mayor relación perímetro:área, distribuidos en el paisaje de forma que se minimicen las distancias desde cada punto del pasto hasta la mancha de bosque más cercana.

Según la literatura, las pequeñas manchas forestales permiten el desplazamiento de los enemigos naturales a través del paisaje (Dramstad et al., 1996, Altieri and Nicholls, 2010), lo que favorecería el encuentro entre el salivazo y sus enemigos naturales. Por lo tanto, son fundamentales para el control biológico de los pastos, como sugieren los análisis estadísticos. Estas pequeñas áreas de bosque, a priori, no son la principal fuente de enemigos naturales de los salivazos, cuyas principales poblaciones se alojarían en áreas forestales más grandes, dependiendo de las necesidades de cada especie. Por consiguiente, estas manchas de bosque deberían estar conectadas con otras áreas forestales de mayor tamaño.

\section{Conclusiones}

\subsection{Recomendaciones para la planificación del paisaje}

Con el fin de maximizar el control biológico proporcionado por el bosque, y considerando la revisión de la literatura y los análisis estadísticos realizados (detallados en Del Arco, 2013), sugerimos:

- Establecer un conjunto integrado de manchas de bosque de diferentes tamaños, con buena conectividad entre ellas, para permitir el movimiento de los enemigos naturales a través del paisaje. Especialmente se debe favorecer la 
conectividad con grandes manchas de bosque, que serán, a priori, las principales fuentes de enemigos naturales.

- Mantener distancias desde cada punto dentro del pasto a la mancha de bosque más cercana, y entre manchas, de menos de $50 \mathrm{~m}$, para promover, respectivamente, el control biológico y la conectividad.

\subsection{Consideraciones y recomendaciones para Políticas Públicas}

- Según los resultados de este estudio, la conservación/recuperación planificada de manchas de bosque en el entorno y en el interior de los pastos sería potencialmente beneficiosa para la actividad ganadera del municipio de Cotriguaçu, además de para la conservación del bosque nativo. Por tanto podría favorecer una mayor conciliación del desarrollo económico local con la conservación de la biodiversidad y de los servicios ecosistémicos en las áreas de producción pecuaria del municipio.

- El efecto mosaico sobre la reducción del nivel de infestación de salivazos y otras plagas podría multiplicarse en todo el paisaje a nivel municipal o regional, favoreciendo estrategias más amplias de gestión del uso de la tierra, incluyendo la conectividad de grandes fragmentos forestales. La información generada y recopilada podría ser un aporte valioso para la toma de decisiones sobre la planificación del paisaje en el Noroeste de Mato Grosso.

\section{Agradecimientos}

Los autores desean agradecer la financiación del proyecto POLICYMIX (http: nina.policymix.no) financiado por la Comisión Europea, Dirección General de Investigación, dentro del $7^{\circ}$ Programa Marco de IDT, Tema 2 - Biotecnología, Agricultura y Alimentación (Grant $\mathrm{n}^{\circ}$ 244065). El Instituto de Ciencia y Tecnología en Políticas Públicas, Estrategias y Desarrollo (INCT-PPED) proporcionó apoyo financiero adicional para el trabajo de campo del autor principal.

\section{Bibliografía}

Agrosuisse, 2010. Diagnostico da pecuaria no municipio de Cotriguaçu-MT. Relatorio final. V.01. Agrosuisse, Rio de Janeiro.

Altieri, M.A., 1999. The ecological role of biodiversity in agroecosystems. Agriculture, Ecosystems and Environment 74, 19-31. https://doi.org/10.1016/S0167-8809(99)00028 -6

Altieri, M.A., Nicholls, C.I., 2010. Disenhos agroecológicos para aumentar La biodiversidad de entomofauna benéfica en agroecosistemas. Sociedad Científica Latinoamericana de Agroecología, Medellín.

Anualpec, 2010. Anuário da Pecuária Brasileira. Instituto FNP, São Paulo.

Del Arco, P., 2013. O efeito da proximidade da floresta no controle biológico da pastagem 
no noroeste de Mato Grosso: uma análise custo-benefício para políticas de uso do solo. Tesis de maestría. Universidad Federal de Rio de Janeiro.

Dramstad, W.E., Olson, J.D., Forman, R.T.I., 1996. Landscape Ecology Principles in Landscape Architecture and Land-use Planning. Island Press, Washington, DC.

Driesche, R.G.V., 2007. Control de plagas y malezas por enemigos naturales. The Forest Health Technology Enterprise Team (FHTET-USDA), Washington, D.C.

IBGE, 2006. Censo agropecuário 2006. Agricultura familiar: primeiros resultados. Instituto Brasileiro de Geografia e Estatística (IBGE), Rio de Janeiro.

Margulis, S., 2003. Causas do Desmatamento da Amazônia Brasileira, $1^{\text {a }}$ ed. Banco Mundial, Brasília. 100p.

Montoya, L.J., Baggio, A.J., 1992. Estudo econômico da introdução de mudas altas para sombreamento de pastagens. In: Encontro Brasileiro de Economia e Planejamento Florestal, 2. Curitiba. Anais. Colombo: Embrapa Florestas 1, 171-191.

Porfirio da Silva, V., 2006. Arborização de pastagens: I - Procedimentos para introdução de árvores em pastagens Convencionais. Colombo: Embrapa Florestas.

Rodrigues, E., 1998. Efeito de bordas em fragmentos de floresta. Cadernos de Biodiversidade. Instituto Ambiental do Paraná, IAP. Curitiba.

Reydon, B.P., 2011. O desmatamento da floresta Amazônica: causas e soluções. Política Ambiental 1(8), 143-155.

Silva, J.A.A., Nobre, A.D., Manzatto, C.V., Joly, C.A., Rodrigues, R.R., Skorupa, L.A., Nobre, C.A., Ahrens, S., May, P.H., Sá, T.D.A., Cunha, M.C., Rech'filho, E.L., 2011. O Código Florestal e a Ciência: contribuições para o diálogo. São Paulo: Sociedade Brasileira para o Progresso da Ciência, SBPC; Academia Brasileira de Ciências, ABC.

Sujii, E.R., Garcia, M.A., Gouveia Fontes, E.M. 2000. Movimentos de migração e dispersão de adultos da cigarrinha-das-pastagens. Pesqui. Agropecu. Bras. 35(3), 471-480. https:// doi.org/10.1590/S0100-204X2000000300001

Townsend, C.R., Magalhães, J.A., Costa, N.L., Pereira, R.G.A., Silva Netto, F.G., 2003. Condições térmicas ambientais sob diferentes sistemas silvipastoris na Amazônia ocidental. Pasturas Tropicales 25(3), 42-44.

Valério, J.R., 2002. Monitoramento de espécies e de níveis populacionais de cigarrinhasdas-pastagens na região centro-norte do país. Embrapa Gado de Corte, Campo Grande.

Valério, J.R., 2009. Cigarrinhas das pastagens. Embrapa Gado de Corte, Campo Grande. Documentos 
